\title{
Multiplicação in vitro de Tapirira guianensis Aubl. (Anacardiaceae)
}

\author{
Ingrid Estefania Mancia de Gutiérrez', Cristina Ferreira Nepomuceno², Tecla dos Santos Silva ${ }^{3}$, \\ Priscila Tavares Fonseca ${ }^{3}$, Vania Celene Alecrim Campos ${ }^{3}$,Bruno Freitas Matos Alvim ${ }^{3}$, \\ Fernando dos Santos Carneiro ${ }^{3}$, Mara Márcia Sampaio Albuquerque ${ }^{3}$, José Raniere Ferreira de Santana ${ }^{4}$
}

\begin{abstract}
RESUMO
Tapirira guianensis possui grande relevância medicinal, ecológica e socioeconômica, ocorrendo em todo o território brasileiro. O objetivo deste estudo foi estabelecer e determinar as melhores condições para a sua multiplicação in vitro. Os explantes, segmentos nodais, cotiledonares e epicótilos, oriundos de plântulas germinadas in vitro, foram testados em concentrações de 6-benzilaminopurina (BAP) e, ou, ácido naftalenoacético (ANA), em meio de cultura WPM. As características avaliadas foram a percentagem de explantes responsivos, o número de brotos e de gemas, o comprimento dos brotos e a matéria seca da parte aérea, aos 30 e 60 dias após inoculação. Foi observado que o segmento cotiledonar, nas condições deste estudo, foi o explante mais indicado para a multiplicação, não havendo indução de brotos adventícios nos epicótilos. O tratamento com 1,0 $\mathrm{mg} \mathrm{L}^{-1}$ de BAP na ausência de ANA é o mais responsivo para a regeneração de T. guianensis.
\end{abstract}

Palavras-chave: lenhosa medicinal, propagação in vitro, regeneração, organogênese direta.

\section{ABSTRACT}

\section{In vitro multiplication of Tapirira guianensis Aubl. (Anacardiaceae)}

Tapirira guianensis is of great medicinal, ecological and socio-economical importance occurring throughout the Brazilian territory. The objective of this study was to establish and determine the best conditions for the in vitro multiplication of $T$. guianensis. The explants nodal, cotyledonary and epicotyl segments from seedlings germinated in vitro were tested in diverse concentrations of 6-benzilaminopurine (BAP) and/or napthaleneacetic acid (NAA) in medium WPM. The following parameters were evaluated: the percentage of responsive explants, the number of shoots and buds, and the length of shoots and shoot dry mass at 30 and 60 days after inoculation. The cotyledonary segment, under these conditions, is the most suitable explant for the multiplication, with no induction of adventitious buds in epicotyl. The treatment with $1.0 \mathrm{mg} \mathrm{L}^{-1} \mathrm{BAP}$ in the absence of NAA is the most responsive to the T. guianensis regeneration.

Key words: medicinal woody, in vitro propagation, regeneration, direct organogenesis.

Recebido para publicação em 23/03/2012 e aprovado em 08/01/2013.

${ }^{1}$ Farmacêutica, Mestre. Departamento de Ciências Biológicas, Universidade Estadual de Feira de Santana, Avenida Transnordestina, s/n, 44036-900, Feira de Santana, Bahia, Brasil.far_gutierrez@yahoo.com.br (autor para correspondência)

${ }^{2}$ Bióloga, Doutora. Departamento de Ciências Biológicas, Universidade Estadual de Feira de Santana, Avenida Transnordestina, s/n, 44036-900, Feira de Santana, Bahia, Brasil. nepomucenocf@yahoo.com.br

${ }^{3}$ Biólogos, Mestres. Departamento de Ciências Biológicas, Universidade Estadual de Feira de Santana, Avenida Transnordestina, s/n, 44036-900, Feira de Santana, Bahia, Brasil. silva.stecla@gmail.com; pristavares25@hotmail.com; vaniaalecrim@hotmail.com; brunoalvim18@yahoo.com.br; fernandobramar@yahoo.com.br; maramarcia_uefs@yahoo.com.br. ${ }^{4}$ Engenheiro-Agrônomo, Doutor. Departamento de Ciências Biológicas, Universidade Estadual de Feira de Santana, Avenida Transnordestina, s/n, 44036-900, Feira de Santana, Bahia, Brasil. raniere@uefs.br 


\section{INTRODUÇÃO}

Tapirira guianensis Aubl. (Anacardiaceae), popularmente conhecida como pau-pombo ou cipiúva, é uma árvore nativa, com ampla distribuição no país (Silva-Luz \& Pirani, 2010). A população emprega suas cascas e folhas para fins ritualísticos (Almeida et al., 2007) e em práticas caseiras da medicina popular, para tratar problemas de pele (Souza \& Felfili, 2006).

Extratos de folhas, sementes e cascas de T. guianensis apresentaram atividade citotóxica, sendo promissor o uso contra diversas linhagens de células tumorais (David et al., 1998; Taylor et al., 2006; Mahmoud et al., 2011). Além dessa, a atividade in vitro antileishmaniose, antimalárica, antibacteriana e antifúngica foram detectadas, para substâncias isoladas do extrato clorofórmico das suas cascas (Roumy et al., 2009).

A espécie normalmente é empregada no reflorestamento de áreas degradadas, principalmente de locais úmidos (Lorenzi, 1992), graças à fácil adaptação a esse ambiente e à produção de frutos, que são altamente apreciados pela fauna (Lenza \& Oliveira, 2005). Sua madeira tem aplicação na construção e obtenção de energia (Cunha \& Albuquerque, 2006), o que torna a planta uma fonte alternativa de renda para as comunidades. Esse elevado potencial madeireiro de $T$. guianensis faz com que o vegetal esteja listado na Portaria $n^{\circ}$ 67, no qual é estabelecido o preço mínimo para a comercialização dos produtos advindos de sua madeira (SEFAZ, 2011).

Nesse contexto, a Cultura de Tecidos Vegetais, por micropropagação ou propagação in vitro, apresenta-se como uma alternativa viável para a produção de mudas, utilizadas em programas de reflorestamento ou plantio comercial da espécie, reduzindo a pressão sobre áreas nativas, nas quais impera o extrativismo, além de se obter e atender às exigências das entidades certificadoras e às necessidades dos produtores de mudas de qualidade. Segundo George (2008), a técnica permite a multiplicação rápida de genótipos, selecionados por maior produtividade, uniformidade e desempenho no campo, sendo uma importante ferramenta na propagação de mudas sadias, em tempo e espaço físico reduzidos. Diversas espécies de plantas medicinais têm sido micropropagadas com o intuito de aumentar a produção de metabólitos de interesse, quer seja por estímulo químico ou por manipulação das condições no microambiente da cultura in vitro (Moyo et al., 2011), a exemplo de algumas lenhosas, como Ephedra procera C.A. Mey., Syzygium cordatum Hochst. e Aquilaria hirta Ridl. (Parsaeimehr et al., 2010; Dewir et al., 2011; Hassan et al., 2011).

Diante do grande potencial medicinal, ecológico e socioeconômico de T. guianensis, faz-se necessário desenvolver metodologias para a multiplicação eficiente, conservação e preservação desta espécie. Até o momen- to, inexistem estudos, na literatura, sobre a propagação vegetativa em espécies de Tapirira. Por esse motivo, o presente trabalho objetivou avaliar a indução de brotos adventícios em explantes de plântulas assépticas de $T$. guianensis, obtidas in vitro.

\section{MATERIAL E MÉTODOS}

\section{Obtenção de explantes a partir de sementes}

Os frutos maduros de T. guianensis foram coletados, em março de 2009, no município de Mata de São João, Bahia. Os frutos foram levados para o Laboratório de Cultura de Tecidos Vegetais, da Universidade Estadual de Feira de Santana, onde foram selecionados, sendo descartados os que continham qualquer rasura no seu epicarpo. Os frutos íntegros foram lavados abundantemente em água corrente e detergente, sendo o último enxágue realizado com água destilada; em seguida, foram desinfestados em câmara de fluxo laminar, por imersão em etanol, a 70\%, durante três minutos; em solução de cloro ativo, a $2,5 \%$, contendo cinco gotas de detergente neutro, por 30 minutos e, por fim, lavadas sucessivas vezes em água estéril. Em seguida, foi realizado o despolpamento dos frutos, em placas de Petri, na ausência de água, com o auxílio de pinça e bisturi. As sementes foram desinfestadas em etanol, a 70\%, durante um minuto; em solução de cloro ativo a 2,5\%, por 15 minutos, seguidas de sucessivas lavagens em água estéril. Dez sementes foram, então, inoculadas em placas de Petri, contendo papel germitest previamente esterilizado e umedecido com água estéril, e fechadas com filme de polivinilcloreto (PVC). Após 15 dias da inoculação, quando as primeiras raízes haviam sido emitidas, as plântulas que não apresentaram contaminação microbiana foram transferidas para tubos de ensaio, contendo meio de cultura WPM (Lloyd \& McCown, 1980), permanecendo por mais 30 dias, até a coleta dos explantes.

\section{Indução de brotos a partir de explantes}

$\mathrm{Na}$ multiplicação in vitro, três tipos de explantes foram utilizados (segmento cotiledonar, epicótilo e segmento nodal), os quais foram inoculados em diferentes concentrações de $\operatorname{BAP}\left(0,0 ; 0,5 ; 1,0 ; 1,5\right.$ e $\left.2,0 \mathrm{mg} \mathrm{L}^{-1}\right)$ e ANA $\left(0,0 ; 0,25\right.$ e $\left.0,50 \mathrm{mg} \mathrm{L}^{-1}\right)$.

O delineamento experimental utilizado foi inteiramente casualizado em esquema fatorial $3 \times 5 \times 3$, totalizando 45 tratamentos. Cada tratamento constou de seis repetições, cada uma constituída por quatro tubos de ensaio, cada um dos quais contendo um explante.

Após 30 e 60 dias da inoculação, foram avaliadas as seguintes variáveis: número de brotos por explante, número de gemas do maior broto e comprimento da maior brotação. A matéria seca da parte aérea e a percentagem de explantes responsivos foram avaliadas apenas aos 60 dias da inoculação. 


\section{Condições de cultivo}

O meio de cultura utilizado para o estabelecimento e multiplicação in vitro foi o WPM, solidificado com $0,6 \%$ de Agar (Himediaß) e suplementado com 3\% de sacarose. $\mathrm{O}$ pH foi ajustado para 5,7 $\pm 0,01$ antes da esterilização em autoclave, a $121^{\circ} \mathrm{C}$, por $20 \mathrm{~min}$. Todas as culturas foram incubadas em sala de cultura mantida a $60 \%$ de umidade relativa, temperatura de $25 \pm 2{ }^{\circ} \mathrm{C}$, sob fotoperíodo de $16 \mathrm{~h}$ e uma densidade de fluxo de fótons de $60 \mu \mathrm{mol} \mathrm{m}^{-2} \mathrm{~s}^{-1}$, fornecido por lâmpadas fluorescentes brancas.

\section{Análise estatística}

Os dados foram submetidos à análise de variância (ANOVA) e as médias estatísticas comparadas pelo teste de Scott-Knott, a 5\% de significância, para os fatores qualitativos e ajustes, usando as equações de regressão polinomial para os fatores quantitativos. A análise foi realizada com o software SISVAR (Ferreira, 2008).

\section{RESULTADOS E DISCUSSÃO}

Das 1.600 sementes de T. guianensis inoculadas em Placas de Petri e transferidas para tubos de ensaio, 39,4\% apresentaram contaminação fúngica e, ou, bacteriana. Com o mesmo tempo de imersão em hipoclorito para $T$. guianensis, as sementes de Swietenia macrophylla King apresentaram taxa média de contaminação bacteriana de 26,2\% (Couto et al., 2004). Geralmente, a fase de estabelecimento in vitro de lenhosas é influenciada pela contaminação de micro-organismos endofíticos, não removidos durante a desinfestação superficial do tecido (Harry \& Torpe, 1994). Após os 30 dias de transferência das sementes germinadas para o meio de cultura, percebeu-se que $59,8 \%$ apresentavam crescimento normal, sendo estas plântulas utilizadas para fornecer explantes à etapa de multiplicação.

Na etapa de multiplicação in vitro, observou-se que a interação tripla, para todas as variáveis analisadas, aos 30 e 60 dias, foi significativa ( $p<0,01$ ou $p<0,05$ ), exceto para número de brotos e matéria seca da parte aérea avaliadas aos 60 dias, para cujos resultados houve significância $(\mathrm{p}<0,01)$ para a interação dupla (concentração de BAP x concentração de ANA) (Tabelas 1,2).

Em T. guianensis não foi possível observar, diante dos tratamentos testados, o desencadeamento da capacidade organogênica no explante epicótilo (dados não mostrados). Resultado semelhante foi observado para o hipocótilo de Erythrina velutina Willd., em que o estímulo hormonal com BAP e, ou, ANA, não foi suficiente para favorecer a formação de brotos (Costa et al., 2010). Mui-

Tabela 1. Resumo da análise de variância para percentagem de explantes responsivos (\% ER), número de brotos (NB), número de gemas do maior broto (NG), comprimento da parte aérea (CPA) (cm) e matéria seca da parte aérea (MSPA) (mg) de plântulas de Tapirira guianensis, advindos de segmentos nodais, cotiledonares e epicótilos em diferentes concentrações de BAP $(0,0 ; 0,5 ; 1,0 ; 1,5$ e 2,0 $\left.\mathrm{mg} \mathrm{L}^{-1}\right)$ e ANA $\left(0,0 ; 0,25\right.$ e $\left.0,50 \mathrm{mg} \mathrm{L}^{-1}\right)$ em meio de cultura WPM aos 30 e 60 dias de inoculação in vitro

\begin{tabular}{lcccc}
\hline \multirow{2}{*}{ FV } & \multicolumn{4}{c}{ Quadrados médios aos 30 dias } \\
\cline { 2 - 5 } & GL & NB ${ }^{\mathbf{z}}$ & NG $^{\mathbf{z}}$ & CPA $^{\mathbf{z}}$ \\
\hline EXP (E) & 1 & $0,351125^{\text {Ns }}$ & $14,688980^{* *}$ & $1,876802^{* *}$ \\
BAP (B) & 4 & $13,448628^{* *}$ & $24,206668^{* *}$ & $2,332831^{* *}$ \\
ANA (A) & 2 & $13,279042^{* *}$ & $14,102417^{* *}$ & $1,618260^{* *}$ \\
E X B & 4 & $0,993095^{*}$ & $2,985136^{* *}$ & $0,344117^{* *}$ \\
E X A & 2 & $0,445902^{\text {Ns }}$ & $1,520375^{\text {Ns }}$ & $0,098749^{\text {Ns }}$ \\
B X A & 8 & $4,993683^{* *}$ & $7,345264^{* *}$ & $0,556535^{* *}$ \\
E X B X A & 8 & $0,831309^{*}$ & $1,811659^{* *}$ & $0,265176^{* *}$ \\
Resíduo & 150 & 0,362654 & 0,648246 & 0,071485 \\
CV (\%) & & 41,75 & 39,19 & 48,67 \\
\hline
\end{tabular}

\begin{tabular}{|c|c|c|c|c|c|c|}
\hline \multirow{2}{*}{ FV } & \multicolumn{6}{|c|}{ Quadrados médios aos 60 dias } \\
\hline & GL & $\% \mathrm{ER}^{\mathrm{x}}$ & $\mathbf{N B}^{\mathrm{Z}}$ & NG $^{\mathrm{z}}$ & $\mathrm{CPA}^{\mathrm{z}}$ & MSPA $^{\mathrm{Y}}$ \\
\hline $\mathrm{EXP}(\mathrm{E})$ & 1 & $0,117447 * *$ & $3,138961 *$ & $27,144500 * *$ & $3,181361 * *$ & $0,206843^{\mathrm{NS}}$ \\
\hline BAP (B) & 4 & $0,062709 * *$ & $14,794426 * *$ & $24,803843 * *$ & $2,918199 * *$ & $9,302124 * *$ \\
\hline ANA (A) & 2 & $0,290121 * *$ & $9,790144 * *$ & $7,946351 * *$ & $0,710791 * *$ & $0,296038^{\mathrm{NS}}$ \\
\hline E X B & 4 & $0,044669 * *$ & $0,464629^{\mathrm{NS}}$ & $1,890246^{\mathrm{NS}}$ & $0,264513^{\mathrm{NS}}$ & $0,549365^{\mathrm{NS}}$ \\
\hline E X A & 2 & $0,015442^{\mathrm{NS}}$ & $0,752457^{\mathrm{NS}}$ & $3,956045^{*}$ & $0,401291^{\mathrm{NS}}$ & $0,294962^{\mathrm{NS}}$ \\
\hline B X A & 8 & $0,096957 * *$ & $4,022554 * *$ & $10,229870 * *$ & $0,862850 * *$ & $0,861789 * *$ \\
\hline E X B X A & 8 & $0,037246^{* *}$ & $0,924982^{\mathrm{NS}}$ & $2,703607 *$ & $0,355168^{*}$ & $0,175036^{\mathrm{NS}}$ \\
\hline Resíduo & 150 & 0,008610 & 0,517422 & 1,149977 & 0,148294 & 0,252198 \\
\hline CV (\%) & & 19,69 & 42,72 & 36,05 & 46,72 & 20,59 \\
\hline
\end{tabular}

** Significativo a $1 \%$ de probabilidade pelo teste F. * Significativo a $5 \%$ de probabilidade pelo teste F. Ns Não significativo a $5 \%$ de probabilidade pelo teste F. ${ }^{\mathrm{x}}$ Dados transformados em arco-seno $\sqrt{\%} ;{ }^{\mathrm{Y}}$ Dados transformados em $(\mathrm{x}+1)^{0,5} ;{ }^{\mathrm{z}}$ Dados não transformados. 
tos fatores podem influenciar o processo de indução organogênica, como a concentração e os tipos de reguladores vegetais, a idade do explante, o genótipo, as condições físicas do cultivo, a composição e consistência do meio de cultura (Dobránszki \& Silva, 2010).

A taxa responsiva do explante segmento nodal apresentou um comportamento linear crescente, em função do aumento da concentração de BAP na ausência de ANA, podendo ser testadas concentrações acima de $2,0 \mathrm{mg} \mathrm{L}^{-1}$ de BAP (Figura 1A). Para o segmento cotiledonar, na ausência e na menor concentração testada de ANA, não foi possível o ajuste de uma equação significativa com significado biológico, porém observaram-se, com maior frequência, altas taxas responsivas (80-100\%) (Figura 1B).
Neste trabalho, percebeu-se a formação de brotos nos explantes de T. guianensis, mesmo na ausência de reguladores vegetais (Figura 2), o mesmo sendo observado para Aniba rosaeodora Ducke (Jardim et al., 2010) e Syzygium cordatum (Dewir et al., 2011). Todavia, estes resultados discordam dos obtidos para os segmentos nodais de Maclura tinctoria (L.) D. Don ex Steud. (Gomes et al., 2010) e de Myrica esculenta Buch.-Ham. ex D. Don (Bhatt \& Dhar, 2004), nos quais não foi observada a iniciação do processo morfogenético, em meio de cultura ausente de reguladores. Essa maior capacidade morfogenética de alguns tecidos pode ser causada pela variabilidade genética de cada cultura (George \& Debergh, 2008).

Tabela 2. Matéria seca da parte aérea (mg) de Tapirira guianensis inoculada aos 60 dias em meio de cultura WPM, suplementada com diferentes concentrações de $\operatorname{BAP}\left(0,0 ; 0,5 ; 1,0 ; 1,5\right.$ e $\left.2,0 \mathrm{mg} \mathrm{L}^{-1}\right)$ e de $\operatorname{ANA}\left(0,0 ; 0,25\right.$ e $\left.0,5 \mathrm{mg} \mathrm{L}^{-1}\right)$

\begin{tabular}{lrrrrr}
\hline \multirow{2}{*}{$\mathbf{A N A}\left(\mathbf{m g ~ L}^{-\mathbf{1}}\right)$} & $\mathbf{5}$ & $\mathbf{B A P}\left(\mathbf{m g ~ L}^{-\mathbf{1}}\right)$ \\
\cline { 2 - 6 } & $\mathbf{0 , 0}$ & $\mathbf{0 , 5}$ & $\mathbf{1 , 0}$ & $\mathbf{1 , 5}$ & $\mathbf{2 , 0}$ \\
\hline 0,00 & $1,43 \mathrm{~A}$ & $10,87 \mathrm{~A}$ & $4,53 \mathrm{~B}$ & $4,13 \mathrm{~A}$ & $4,80 \mathrm{~A}$ \\
0,25 & $2,05 \mathrm{~A}$ & $8,27 \mathrm{~A}$ & $5,93 \mathrm{~B}$ & $5,79 \mathrm{~A}$ & $6,22 \mathrm{~A}$ \\
0,50 & $3,37 \mathrm{~A}$ & $9,14 \mathrm{~A}$ & $7,80 \mathrm{~A}$ & $3,43 \mathrm{~A}$ & $3,69 \mathrm{~A}$
\end{tabular}

Médias seguidas pela mesma letra, na mesma coluna, não diferem estatisticamente entre si a 5\% de probabilidade pelo teste de Scott-Knott.

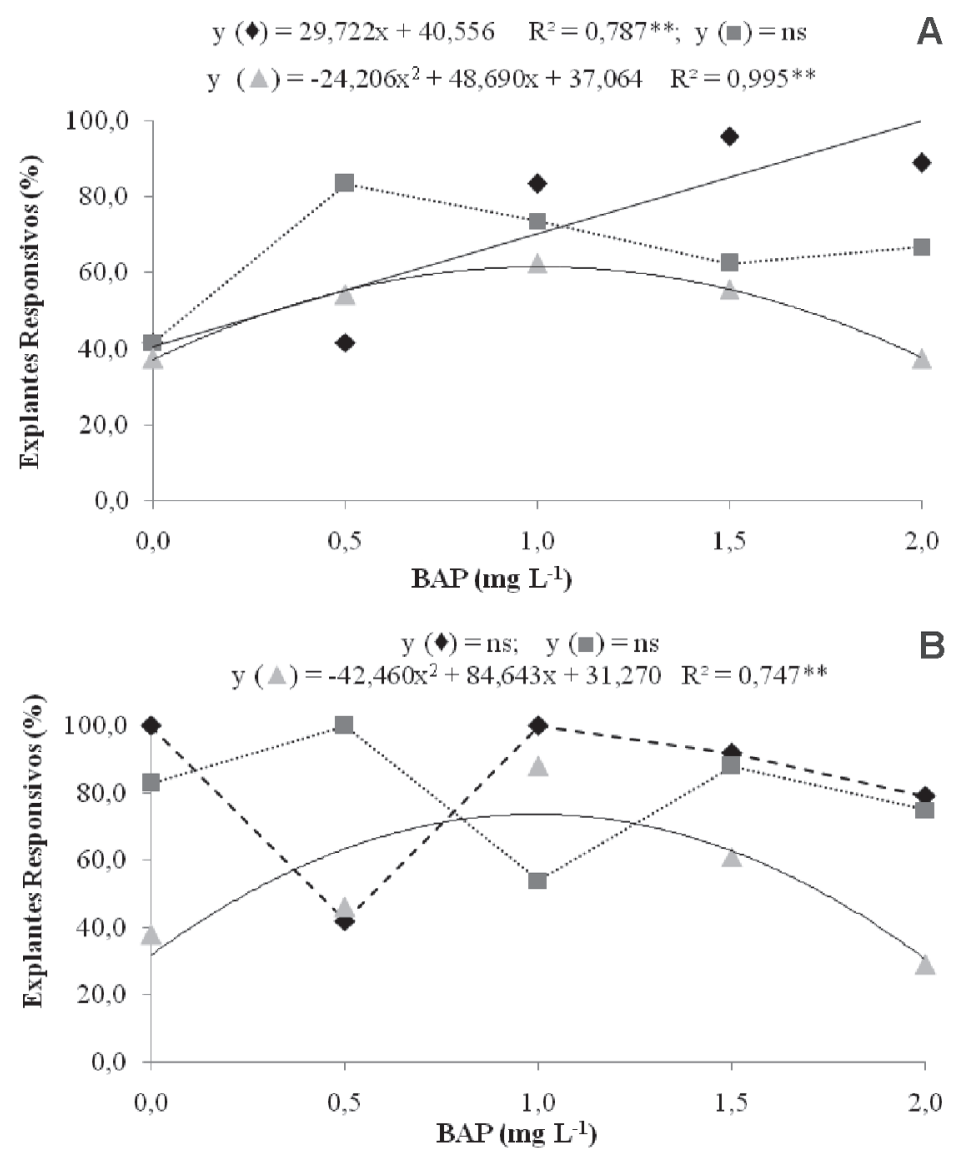

Figura 1. Percentagem de explantes responsivos de Tapirira guianensis, em função da concentração de BAP $(0,0 ; 0,5 ; 1,0 ; 1,5$ e $\left.2,0 \mathrm{mg} \mathrm{L}^{-1}\right)$ e de ANA $\left(\bullet 0,0 ; \boldsymbol{\square} 0,25 \mathrm{e} \boldsymbol{\Delta} 0,5 \mathrm{mg} \mathrm{L}^{-1}\right)$ e dos explantes testados, segmento nodal (A) e segmento cotiledonar (B), aos 60 dias de inoculação em meio de cultura WPM (Nível de significância: ** p < 0,01; * p < 0,05; ns - não significativo). 
O maior número médio de brotos observado $(3,33)$, aos 30 dias de inoculação, ocorreu a partir do segmento nodal. A curva de resposta na ausência de ANA indica que a utilização de BAP, na concentração estimada de $1,33 \mathrm{mg} \mathrm{L}^{-1}$, atinge o maior valor estimado para a variável em análise $(2,83)$ (Figura 2A). O resultado encontrado foi superior ao reportado para Vitis champinii Planch. (Mukherjee et al. 2010), Bauhinia cheilantha (Bong.) Steud. (Gutiérrez et al., 2011a) e Parkia biglobosa (Jacq.) R. Br. ex G. Don (Sambe et al., 2010), em que, na concentração semelhante de BAP testada, o número médio de brotos foi de 1,3, 1,6 e 1,9 por segmento nodal, respectiva- mente. Já para Oroxylum indicum (L.) Kurz, uma média de 7,0 brotos por segmento nodal foi observada na presença de 1,0 $\mathrm{mg} \mathrm{L}^{-1}$ de BAP (Gokhale \& Bansal, 2009). Diante disso, percebe-se que é difícil predizer como os reguladores podem afetar o sistema fisiológico da planta.

Para a mesma variável, a partir do segmento cotiledonar, não foi possível o ajuste de uma equação significativa, com significado biológico, na ausência de ANA, sendo observado o maior número médio de brotos $(3,17)$ na presença de 1,0 mg L-1 de BAP (Figura 2B), resultado superior ao reportado para Parkia biglobosa, para a qual a média do número de brotos foi de 2,08 por segmento
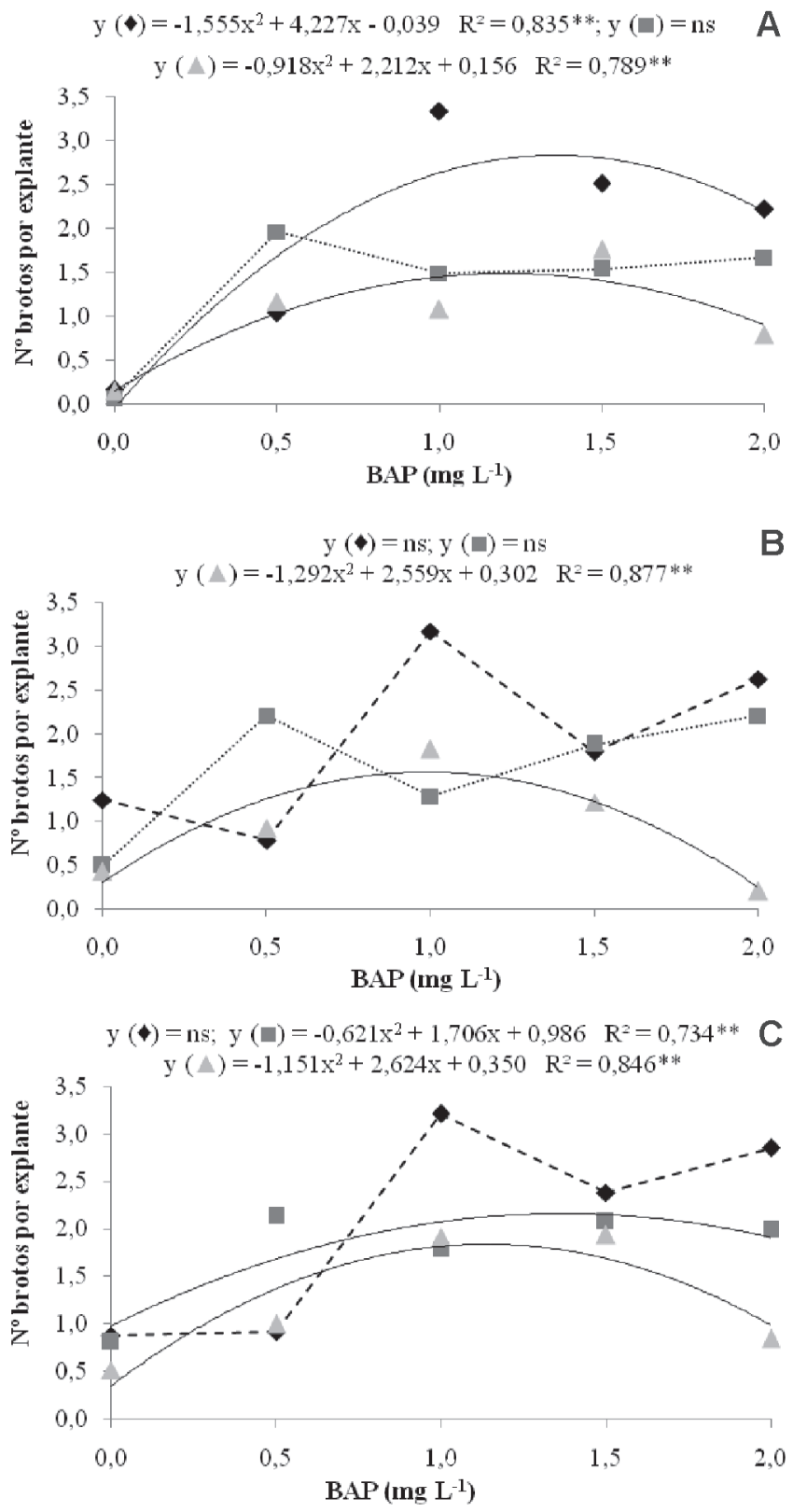

Figura 2. Número de brotos obtidos a partir do segmento nodal (A) e segmento cotiledonar (B) de Tapirira guianensis, em meio de cultura WPM suplementado com diferentes concentrações de BAP $\left(0,0 ; 0,5 ; 1,0 ; 1,5\right.$ e 2,0 $\left.\mathrm{mg} \mathrm{L}^{-1}\right)$ e de ANA $(\bullet 0,0 ; \boldsymbol{\square} 0,25 \mathrm{e}$ $\boldsymbol{\Delta} 0,5 \mathrm{mg} \mathrm{L}^{-1}$ ) aos 30 dias (A, B) e 60 dias da inoculação (C) (Nível de significância: ** $\mathrm{p}<0,01 ; * \mathrm{p}<0,05$; ns - não significativo). 
cotiledonar, em meio de cultura MS, acrescido da mesma concentração de BAP (Sambe et al., 2010).

A interação citocinina e auxina não favoreceu a formação de brotos em T. guianensis; provavelmente, a presença de ANA, nas dosagens testadas, pode ter provocado uma diminuição nos níveis de substâncias endógenas naturais, que promoveriam a divisão celular. A interação também não foi benéfica nas culturas de $B$. cheilantha (Gutiérrez et al., 2011b); já, para Cecropia glaziovii Snethl., a interação permitiu obter uma média de 15 brotações por segmento nodal (Alves, 2010).

Siwach \& Gill (2011) reportaram um número de brotos duas vezes maior aos 60 dias da multiplicação in vitro de Ficus religiosa L., em vez de aos 21 dias, comportamento diferente do observado para T. guianensis, para a qual, aos 60 dias, independentemente do explante utilizado, o maior número médio de brotos $(3,21)$ observado (Figura 2C) assemelha-se ao encontrado aos 30 dias de inoculação.
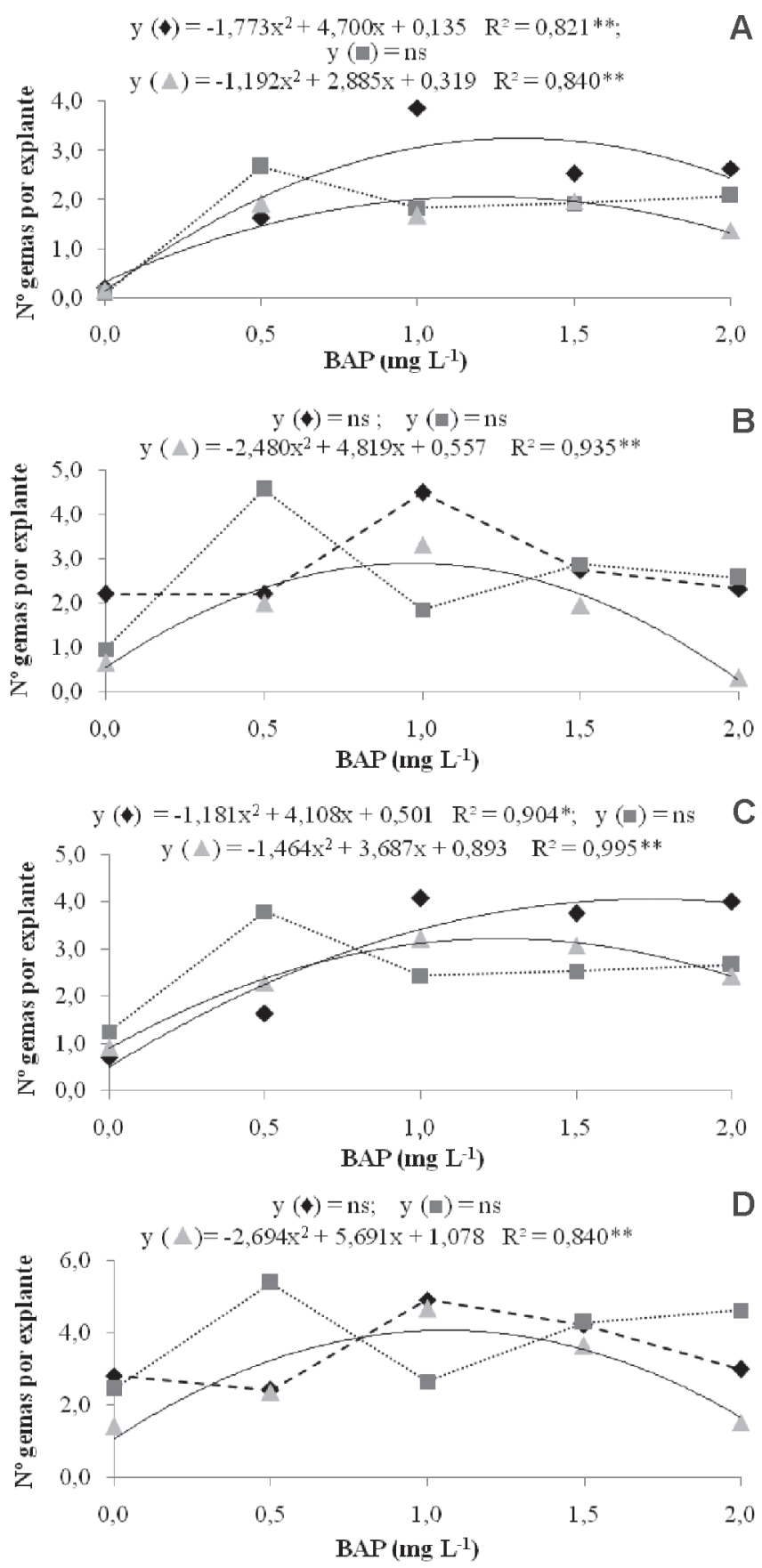

Figura 3. Número de gemas obtidas do maior broto advindas do segmento nodal (A, C) e segmento cotiledonar (B, D) de Tapirira guianensis, em meio de cultura WPM suplementado com diferentes concentrações de BAP $\left(0,0 ; 0,5 ; 1,0 ; 1,5\right.$ e 2,0 mg L $\left.\mathrm{L}^{-1}\right)$ e de ANA $\left(\bullet 0,0 ; \quad 0,25\right.$ e $\left.\boldsymbol{\Delta} 0,5 \mathrm{mg} \mathrm{L}^{-1}\right)$ aos 30 dias (A, B) e 60 dias de inoculação (C, D) (Nível de significância: ** p < 0,01; * p < 0,05; ns - não significativo). 
Aos 30 dias, a curva de resposta na ausência de ANA indicou que o uso de BAP, na concentração de $1,33 \mathrm{mg} \mathrm{L}^{-1}$, permite estimar o maior valor médio $(3,25)$ para número de gemas a partir dos brotos advindos do segmento nodal (Figura 3A). Já, para o segmento cotiledonar foi observado um maior número médio de gemas (4,5) em $1,0 \mathrm{mg} \mathrm{L}^{-1}$ de BAP (Figura 3B), enquanto, aos 60 dias, o maior número de gemas estimado para os brotos advindos de segmento nodal e cotiledonar foi semelhante $(4,1)$, quando na presença estima- da de 1,74 e 1,06 $\mathrm{mg} \mathrm{L}^{-1}$ de BAP, respectivamente (Figuras 3C, 3D). O maior valor, estimado pelas equações quadráticas, para o comprimento dos brotos oriundos de segmentos nodal e cotiledonar, são 9,5 e 10,2 mm, quando o meio de cultura for acrescido de 1,15 e $0,92 \mathrm{mg} \mathrm{L}^{-1}$ de BAP, respectivamente, ambos na ausência de ANA aos 30 dias de inoculação. Incrementos de BAP, em concentrações superiores às concentrações estimadas, tendem a desfavorecer a formação das brotações (Figuras 4A, 4B). Esses resultados divergem dos
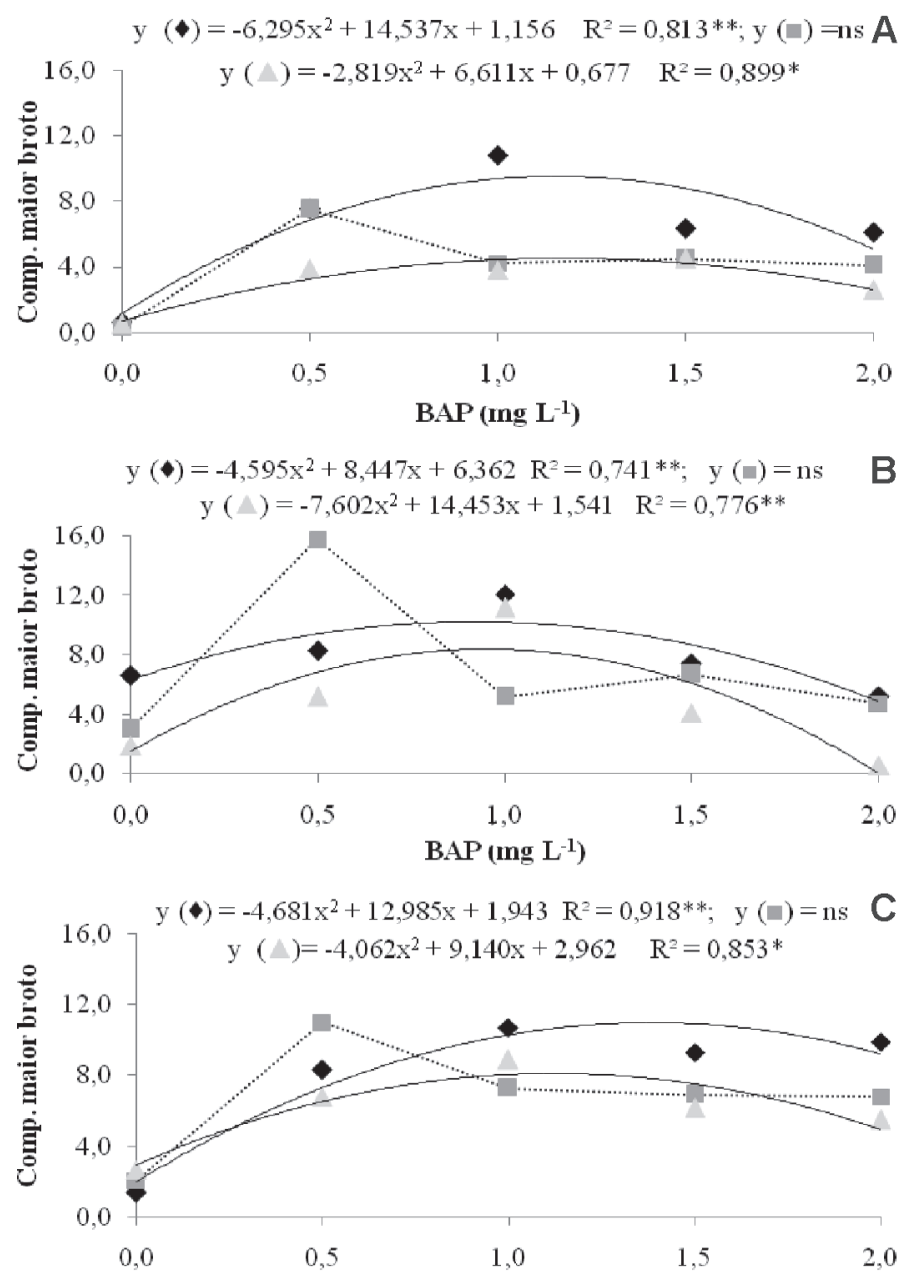

BAP (mg L $\left.\mathbf{L}^{-1}\right)$

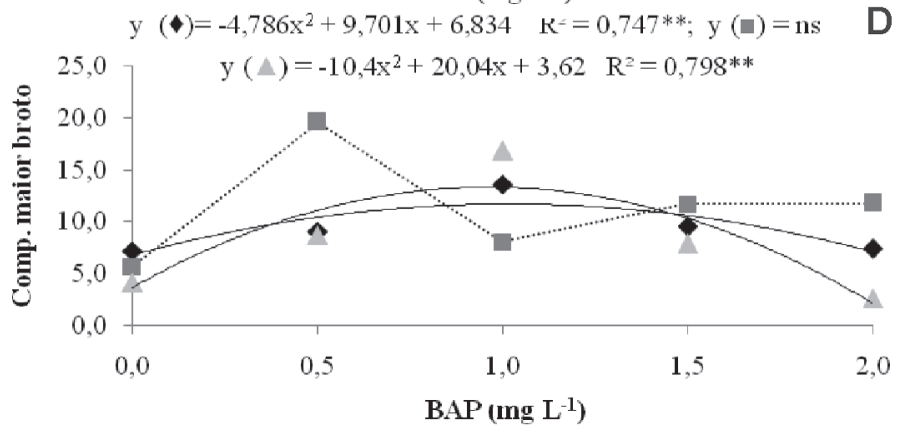

Figura 4. Comprimento do maior broto ( $\mathrm{mm}$ ) advindo de segmento nodal (A, C) e segmento cotiledonar (B, D) de Tapirira guianensis, em meio de cultura WPM suplementado com diferentes concentrações de BAP $\left(0,0 ; 0,5 ; 1,0 ; 1,5\right.$ e $\left.2,0 \mathrm{mg} \mathrm{L}^{-1}\right)$ e de ANA $\left(\diamond 0,0 ; \square 0,25\right.$ e $\left.\boldsymbol{\Delta} 0,5 \mathrm{mg} \mathrm{L}^{-1}\right)$ aos 30 dias (A, B) e 60 dias de inoculação (C, D) (Nível de significância: ** p < 0,01; * p < 0,05; ns - não significativo). 
reportados por Ayub et al. (2010), para os quais as citocininas testadas foram prejudiciais ao desenvolvimento dos brotos, pois as maiores brotações $(1,7 \mathrm{~cm})$ de videira cv. Bordô, a partir de segmento nodal, foram obtidas no meio de cultura $\mathrm{MS} / 2$, na ausência de BAP.

O comprimento médio das brotações de T. guianensis, a partir do segmento cotiledonar, na ausência de ANA, estimado pelas equações quadráticas, aos 60 dias, foi de $11,8 \mathrm{~mm}$, valor semelhante ao do comprimento estimado para o segmento nodal, 10,9 mm (Figuras 4C, 4D). Esses resultados são inferiores aos reportados para cultura de Vitex negundo L., advindos de segmento nodal inoculado em meio MS acrescido de $1,14 \mathrm{mg} \mathrm{L}^{-1}$ de BAP, que apresentaram cerca de $45 \mathrm{~mm}$ de comprimento, aos 56 dias de inoculação (Ahmad \& Anis, 2011), e para culturas de $F$. religiosa, cujas brotações advindas do segmento nodal, em 1,0 $\mathrm{mg} \mathrm{L}^{-1}$ de BAP, mediam $24 \mathrm{~mm}$ de comprimento aos 60 dias (Siwach \& Gill, 2011).

Com relação à variável matéria seca da parte aérea, não foi possível o ajuste de uma equação significativa, com significado biológico, porém, o maior acúmulo massal foi observado em $0,5 \mathrm{mg} \mathrm{L}^{-1}$ de BAP, independentemente da presença de ANA (Tabela 2).

Percebe-se que, para todas as variáveis analisadas na multiplicação in vitro de T. guianensis, não foi observado efeito sinérgico dos reguladores de crescimentos testados. Segundo Staden et al. (2008), a interação pode atuar sinérgica ou antagonicamente, a depender de inúmeras circunstâncias, uma vez que a presença de um determinado regulador pode afetar a biossíntese ou metabolismo de um outro regulador, alterando os níveis das substâncias endógenas, ou ainda os fatores ambientais inerentes ao processo podem modificar as respostas dos reguladores ou, até mesmo, inativá-los.

\section{CONCLUSÃO}

O presente estudo descreveu, pela primeira vez, a multiplicação in vitro para um representante do gênero Tapirira, por meio de um método eficiente para a indução de brotos adventícios, a partir do segmento cotiledonar de T. guianensis, cultivados em meio WPM acrescido de $1,0 \mathrm{mg} \mathrm{L}^{-1}$ de BAP.

\section{REFERÊNCIA}

Ahmad N \& Anis M (2011) An efficient in vitro process for recurrent production of cloned plants of Vitex negundo L. European Journal of Forest Research, 130:135-144.

Almeida MZ, Athayde V, Souza M, Campos G, Cunha C, SilvaFilho A, Gutiérrez I, Costa N, Campello I, Moreira T, Moreira T, Lobo L, Hori L, Sancho T, Figueiredo C, Gois F, Oliveira J \& Furtado V (2007) Levantamento etnobotânico em comunidades terreiros: Manso Dandalungua Cocuazenza. In: $6^{\circ}$ Simpósio de Farmacognosia, Belém. Anais, Jornal Brasileiro de Fitomedicina/APSEN Fitomedicina. p.50
Alves MN (2010) Tissue culture of Cecropia glaziovii Sneth (Urticaceae): vegetative micropropagation and plant regeneration from callus. Ciência e Agrotecnologia, 34:1245-1252.

Ayub RA, Spinardi B, Basso MF \& Biasi LA (2010) Indução de multibrotação in vitro em videira cv. Bordô. Revista Brasileira de Fruticultura, 32:675-681.

Bhatt ID \& Dhar U (2004) Factors controlling micropropagation of Myrica esculenta Buch. - Ham. ex D. Don: a high value wild edible of Kumaun Himalaya. African Journal of Biotechnology, $3: 534-540$.

Costa GM, Nepomuceno CF \& Santana JRF (2010) Propagação in vitro de Erythrina velutina. Ciência Rural, 40:1090-1096.

Couto JMF, Otoni WC, Pinheiro AL \& Fonseca EP (2004) Desinfestação e germinação in vitro de sementes de mogno (Swietenia macrophylla King). Revista Árvore, 28:633-642.

Cunha LVFC \& Albuquerque UP (2006) Quantitative ethnobotany in an atlantic forest fragment of northeastern brazil implications to conservation. Environmental Monitoring and Assessment, 114:1-25.

David JM, Chávez JP, Chai HB, Pezzuto JM \& Cordell GA (1998) Two new cytotoxic compounds from Tapirira guianensis. Journal of Natural Products, 61:287-289.

Dewir YH, Singh N, Mngomezulu S \& Omar AMK (2011) Micropropagation and detection of important triterpenes in in vitro and field grown plants of Syzygium cordatum. Journal of Medicinal Plants Research, 5:3078-3083.

Dobránszki J \& Silva JAT (2010) Micropropagation of apple - A review. Biotechnology Advances, 28:462-488.

Ferreira DF (2008) Sisvar: um programa para análises e ensino de estatística. Revista Científica Symposium, 6:36-41.

George EF (2008) Plant tissue culture procedure - Background. In: George EF, Hall MA \& De Klerk GJ (Eds.) Plant propagation by tissue culture. $3^{\mathrm{a}}$ ed. The Background. Dordrecht, Springer. p.1-28.

George EF \& Debergh PC (2008) Micropropagation: Uses and methods. In: George EF, Hall MA \& De Klerk GJ (Eds.) Plant propagation by tissue culture. $3^{\mathrm{a}}$ ed. The Background. Dordrecht, Springer. p.29-64.

Gokhale M \& Bansal YK (2009) Direct in vitro regeneration of a medicinal tree Oroxylum indicum (L.) Vent. through tissue culture. African Journal of Biotechnology, 8:3777-3781

Gomes GAC, Paiva R, Herrera RC \& Paiva PDO (2010) Micropropagation of Maclura tinctoria L.: an endangered woody species. Revista Árvore, 34:25-30

Gutiérrez IEM, Nepomuceno CF, Ledo CAS \& Santana JRF (2011a) Regeneração in vitro via organogênese direta de Bauhinia cheilantha. Ciência Rural, 41:260-265

Gutiérrez IEM, Nepomuceno CF, Ledo CAS \& Santana JRF (2011b) Micropropagation and acclimatization of Bauhinia cheilantha (an important medicinal plant). African Journal of Biotechnology, 10:1353-1358

Harry IS \& Thorpe TA (1994) In vitro culture of forest trees. In: Vasil IK \& Thorpe TA (Eds.) Plant cell and tissue culture. Dordrecht, Kluwer Academic Publishers. p.539-560.

Hassan NH, Ali NAM, Zainudin F \& Ismail H (2011) Effect of 6benzylaminopurine (BAP) in different basal media on shoot multiplication of Aquilaria hirta and detection of essential oils in the in vitro shoots. African Journal of Biotechnology, 10:10500-10503.

Jardim LS, Sampaio PTB, Costa SS, Gonçalves CQB \& Brandão HLM (2010) Efeito de diferentes reguladores de crescimento na regeneração in vitro de pau-rosa (Aniba rosaeodora Ducke). Acta Amazonia, 40:275-280. 
Lenza E \& Oliveira PE (2005) Biologia reprodutiva de Tapirira guianensis Aubl. (Anacardiaceae), uma espécie dióica em mata de galeria do Triângulo Mineiro, Brasil. Revista Brasileira Botânica, 28:179-190.

Lloyd G \& McCown B (1980) Use of microculture for production and improvement of Rhododendron spp. HortScience, 15:415.

Lorenzi H (1992) Árvores brasileiras: manual de identificação e cultivo de plantas arbóreas nativas do Brasil. São Paulo, Plantarum. 368p.

Mahmoud TS, Marques MR, Pessoa CO, Lotufo LVC, Magalhães HIF, Moraes MO, Lima DP, Tininis AG \& Oliveira JE (2011) In vitro cytotoxic activity of Brazilian Middle West plant extracts. Revista Brasileira de Farmacognosia, 21:456-464.

Moyo M, Bairu MW, Amoo SO \& Staden J (2011) Plant biotechnology in South Africa: Micropropagation research endeavours, prospects and challenges. South African Journal of Botany, 77:996-1011.

Mukherjee P, Husain N, Misra SC \& Rao VS (2010) In vitro propagation of a grape rootstock, de Grasset (Vitis champinii Planch.): Effects of medium compositions and plant growth regulators. Scientia Horticulturae, 126:13-19

Parsaeimehr A, Sargsyan E \& Javidnia K (2010) Influence of plant growth regulators on callus induction, growth, chlorophyll, ephedrine and pseudoephedrine contents in Ephedra procera. Journal of Medicinal Plants Research, 4:1308-1317.

Roumy V, Fabre N, Portet B, Bourdy G, Acebey L, Vigor C, Valentin A \& Moulis C (2009) Four anti-protozoal and anti-bacterial compounds from Tapirira guianensis. Phytochemistry, 70:305311
Sambe MAN, Sagna M \& Sy MO (2010) Seed germination and in vitro plant regeneration of Parkia biglobosa (Jacq.) Benth. African Journal of Biotechnology, 9:3099-3108.

SEFAZ (2011) Portaria N 067/2011 “Institui Lista de Preços Mínimos para os produtos oriundos da Indústria Florestal e Extrativa Vegetal". Disponível em: <http:// app1.sefaz.mt.gov.br>. Acessado em: 20 de fevereiro de 2012.

Silva-Luz CL \& Pirani JR (2010) Anacardiaceae in Lista de Espécies da Flora do Brasil. Jardim Botânico do Rio de Janeiro. Disponível em: <http://floradobrasil.jbrj.gov.br/2010/ FB004408>. Acessado em: 12 de janeiro de 2012.

Siwach P \& Gill AR (2011) Enhanced shoot multiplication in Ficus religiosa $\mathrm{L}$. in the presence of adenine sulphate, glutamine and phloroglucinol. Physiology and Molecular Biology of Plants, $17: 271-280$

Souza CD \& Felfili JM (2006) Uso de plantas medicinais na região de Alto Paraíso de Goiás, GO, Brasil. Acta Botanica Brasilica, 20:135-142.

Staden J, Zazimalova E \& George EF (2008) Plant growth regulators II: Cytokinins, their analogues and antagonists. In: George EF, Hall MA \& De Klerk GJ (Eds.) Plant propagation by tissue culture. $3^{\mathrm{a}}$ ed. Dordrecht, Springer. p.205-226.

Taylor PG, Cesari IM, Arsenak M, Ballen D, Abad MJ, Fernández A, Milano B, Ruiz MC, Williams B \& Michelangeli F (2006) Evaluation of Venezuelan medicinal plant extracts for antitumor and antiprotease activities. Pharmaceutical Biology, 44:349362 . 